\title{
Cutoff value determines the performance of a semi-quantitative immunochemical faecal occult blood test in a colorectal cancer screening programme
}

\author{
LGM van Rossum ${ }^{*, 1}$, AF van Rijn², RJF Laheij', MGH van Oijen', P Fockens ${ }^{2}$, JBMJ Jansen', ALM Verbeek ${ }^{3}$ and \\ E Dekker ${ }^{2}$
}

'Department of Gastroenterology and Hepatology, Radboud University Nijmegen Medical Center, P.O.Box 910 I, 6500 HB, Nijmegen, The Netherlands; ${ }^{2}$ Department of Gastroenterology and Hepatology, Academic Medical Center, University of Amsterdam, Amsterdam, The Netherlands; ${ }^{3}$ Department of Epidemiology and Biostatistics and MTA, Radboud University Nijmegen Medical Center, Nijmegen, The Netherlands

BACKGROUND:The cutoff of semi-quantitative immunochemical faecal occult blood tests (iFOBTs) influences colonoscopy referrals and detection rates. We studied the performance of an iFOBT (OC-Sensor) in colorectal cancer (CRC) screening at different cutoffs. METHODS: Dutch screening participants, 50-75 years of age, with average CRC risk and an iFOBT value $\geqslant 50 \mathrm{ng} \mathrm{ml}^{-1}$ were offered colonoscopy. The detection rate was the percentage of participants with CRC or advanced adenomas ( $\geqslant 10 \mathrm{~mm}, \geqslant 20 \%$ villous, high-grade dysplasia). The number needed to scope (NNTScope) was the number of colonoscopies to be carried out to find one person with CRC or advanced adenomas.

RESULTS: iFOBT values $\geqslant 50 \mathrm{ng} \mathrm{ml}^{-1}$ were detected in 526 of 6157 participants (8.5\%) and 428 (8I\%) underwent colonoscopy. The detection rate for advanced lesions (28 CRC and I6I with advanced adenomas) was 3.1\% (95\% confidence interval: $2.6-3.5 \%$ ) and the NNTScope was 2.3. At $75 \mathrm{ng} \mathrm{ml}^{-1}$, the detection rate was $2.7 \%$, the NNTScope was 2.0 and the CRC miss rate compared with $50 \mathrm{ng} \mathrm{ml}^{-1}$ was $<5 \%(\mathrm{~N}=1)$. At $100 \mathrm{ng} \mathrm{ml}^{-1}$, the detection rate was $2.4 \%$ and the NNTScope was $<2$. Compared with $50 \mathrm{ng} \mathrm{ml}^{-1}$, up to $200 \mathrm{ng} \mathrm{ml}^{-1}$ CRC miss rates remained at $16 \%(\mathrm{~N}=4)$.

CONCLUSIONS: Cutoffs below the standard $100 \mathrm{ng} \mathrm{ml}^{-1}$ resulted in not only higher detection rates of advanced lesions but also more colonoscopies. With sufficient capacity, $75 \mathrm{ng} \mathrm{ml}^{-1}$ might be advised; if not, up to $200 \mathrm{ng} \mathrm{ml}^{-1} \mathrm{CRC}$ miss rates are acceptable compared with the decrease in performed colonoscopies.

British Journal of Cancer (2009) I I I, 1274- I28I. doi:10.1038/sj.bjc.6605326 www.bjcancer.com

Published online 15 September 2009

(c) 2009 Cancer Research UK

Keywords: colorectal cancer; faecal occult blood test; screening; epidemiology; colonoscopy

Compared with the guaiac-based FOBT (G-FOBT), one of the main advantages of some immunochemical faecal occult blood tests (iFOBTs) is that they allow haemoglobin quantification (Itoh et al, 1996; Castiglione et al, 2002; Guittet et al, 2007). The semi-quantitative nature of these tests permits adjustment of the cutoff value for the detection of colorectal cancer (CRC) in an effort to optimise screening programmes for specific populations and health-care practices. Changing the cutoff value can have considerable implications on the performance of the test in a screening population. In general, lowering the cutoff value will increase sensitivity, but consequently decrease specificity and vice versa. An increase in sensitivity means an increase in the detection of patients with colorectal cancer or advanced adenomas, but the consequential decrease in specificity results in more persons without relevant lesions undergoing a colonoscopy (false positives). Some studies in screening populations have been

*Correspondence: Dr LGM van Rossum;

E-mail: I.vanrossum@mdl.umcn.nl

Revised 16 July 2009; accepted 21 August 2009; published online 15 September 2009 published on changing the cutoff value of iFOBTs. However, in these studies only a few selected cutoff values are presented, and the complete range of possible cutoff values is not addressed (Castiglione et al, 2002; Guittet et al, 2007; Grazzini et al, 2009). Furthermore, colonoscopy data, verifying the presence or absence of pathology, are usually presented for test results equal to or above the threshold that is recommended by the manufacturer. The two most frequently presented quantitative iFOBTs, the OC-Sensor (Eiken Chemical) and the Magstream 1000 (Fujirebio Diagnostics, Tokyo, Japan), were developed in Japan, where incidence rates for CRC are lower than those in Europe (Minami et al, 2006). Therefore, the cutoff value with optimal overall performance may be different in Europe compared with Japan. In a recent study including 1000 symptomatic and other high-risk patients in Israel, cutoff values below the recommended threshold of $100 \mathrm{ng} \mathrm{ml}^{-1}$ were evaluated (Levi et al, 2007). The authors concluded that the optimal cutoff value might be as low as $75 \mathrm{ng} \mathrm{ml}^{-1}$; they also noted that the test performance in averagerisk patients in a screening population is unknown. Our aim was to evaluate the performance and efficiency of a semi-quantitative iFOBT in an average-risk screening population. 


\section{MATERIALS AND METHODS}

\section{Design and population}

Details of study design and of most materials and methods relevant for this study are published elsewhere (Van Rossum et al, 2008). The study was primarily designed as a randomised controlled trial in an average-risk screening population between 50 and 75 years of age comparing a G-FOBT with an iFOBT. Here, we only describe data of the semi-quantitative iFOBT, OC-Sensor, to evaluate the performance of the iFOBT at different cutoff values in a population-based CRC screening. The name and address of invited subjects were randomly retrieved from municipal databases and the iFOBT was sent directly with the screening invitation. After 2 weeks, a single written reminder was sent. For detailed information regarding the randomisation and invitation procedure, we refer to the earlier publication (Van Rossum et al, 2008).

\section{iFOBT}

In this study, the automated semi-quantitative OC-Sensor (Eiken Chemical Co., Tokyo, Japan) was used. Faecal samples, preserved in a plastic container in a liquid buffer, were processed using an OC-Micro instrument (Eiken Chemical Co.) (Levi et al, 2007). As threshold for positivity of the test, the manufacturer recommends a cutoff value of $100 \mathrm{ng} \mathrm{ml}^{-1}$, which has been applied in several studies (Castiglione et al, 2002; Grazzini et al, 2004; Sohn et al, 2005; Chiang et al, 2006; Fenocchi et al, 2006; Rubeca et al, 2006; Van Rossum et al, 2008). The literature and data provided by the manufacturer show that the test results of the OC-Sensor are reliable in the range from 50 to $2000 \mathrm{ng} \mathrm{ml}^{-1}$ (Vilkin et al, 2005), but in rare cases, the results measured can be much higher. In a previous publication, we compared the G-FOBT Hemoccult with the iFOBT OC-Sensor (Van Rossum et al, 2008). In that publication, for generalisability with previous studies, we presented data for the iFOBT with a fixed cutoff value of $100 \mathrm{ng} \mathrm{ml}^{-1}$. However, we invited all patients with an iFOBT result of $\geqslant 50 \mathrm{ng} \mathrm{ml}^{-1}$ for colonoscopy, which data we use in this analysis. Below $50 \mathrm{ng} \mathrm{ml}^{-1}$, test results may become gradually more unreliable and, to our knowledge, no data on test reliability are available for cutoff levels below $50 \mathrm{ng} \mathrm{ml}^{-1}$, corresponding with $\pm 10 \mu \mathrm{gg}^{-1}$ faeces (Levi et al, 2007).

\section{Colonoscopy}

Colonoscopy was offered to all iFOBT-positive patients. All colonoscopies were carried out by experienced gastroenterologists using conscious sedation with midazolam and fentanyl. If the caecum could not be reached at the initial colonoscopy, the procedure was repeated using propofol anaesthesia, or a computerised tomography colonoscopy was carried out (followed by a second colonoscopy if necessary).

During colonoscopy, all polyps and colorectal cancer were removed if possible, and other lesions were biopsied if necessary. Advanced adenomas were defined as adenomas with a size of $\geqslant 10 \mathrm{~mm}$, adenomas with a villous component of $\geqslant 20 \%$, or adenomas with high-grade dysplasia. The villous component was judged by an experienced pathologist as being either completely villous or $\geqslant 20 \%$ villous or $<20 \%$ villous: if in doubt, a second opinion from another experienced GI pathologist was requested until consensus was reached. A similar consensus strategy was applied for high-grade dysplasia. Each CRC patient was staged according to the American Joint Committee on Cancer system (AJCC), also called the TNM system, which describes stages using Roman numerals I, II, III and IV (O'Connell et al, 2004). According to the Vienna Classification, carcinoma in situ or intramucosal carcinoma was not classified as CRC (Schlemper et al, 2000).

\section{Data analysis}

In population-based colorectal cancer screening, only iFOBTpositive participants are followed-up with colonoscopy. Sensitivity is therefore not available in our study design. Specificity can be quite reliably estimated under the rare disease assumption as 1 minus the number of false positives relative to the total number of participants reduced by the number of true positives, disregarding the number of false FOBT-negative patients (negatives). (Brecht and Robra, 1987) We used detection rates and numbers needed to scope to evaluate the performance of iFOBT at different cutoff levels. Participants were defined as subjects who responded to the invitation by returning a used iFOBT. The detection rate, defined as the percentage of participants with colorectal cancer or $\geqslant 1$ advanced adenomas, was used to describe the yield of the test. Positivity rate was the percentage of positive participants and colonoscopy rate was the percentage of positive participants adherent to colonoscopy. Cancer miss rate was defined as the percentage of cancer patients missed relative to the number of cancer patients at the minimal cutoff value of $50 \mathrm{ng} \mathrm{ml}^{-1}$ of the iFOBT. The expense of the test was captured with the number needed to scope (NNTScope), representing the delicate ratio between true positives (all endoscoped iFOBT positives with CRC or $\geqslant 1$ advanced adenomas) and false positives (no or only minor neoplasia). The NNTScope as a reciprocal of the positive predictive value $(\mathrm{PPV})(\mathrm{NNTS}$ cope $=1 / \mathrm{PPV})$ is defined as the number of persons undergoing a colonoscopy to detect one person with CRC or $\geqslant 1$ advanced adenomas.

Detection rates and NNTScope were calculated and reported with 95\% CI. In figures, detection rates and NNTScope are presented relative to the amount of haemoglobin $\left(\mathrm{ng} \mathrm{ml}^{-1}\right)$ on a continuous scale. Normal distribution of the iFOBT result was achieved by logarithmic transformation. The logarithmic mean difference in the amount of haemoglobin found in patients without cancer or advanced adenomas compared with that in patients with CRC or $\geqslant 1$ advanced adenoma was analysed with logistic regression analysis and reported with $P$-values. The influence of gender and age on logarithmic mean difference was evaluated with multivariable logistic regression analysis. Statistical analysis was carried out with SAS system for windows, software version 8.02 (SAS Institute Inc., Cary, NC, USA).

\section{Ethical approval and consent}

The study was ethically reviewed and approved by the Dutch Health Council (2005/03WBO, The Hague, The Netherlands). All participants gave written informed consent for the iFOBT and, if positive, for colonoscopy.

\section{RESULTS}

Overall, $6157(60 \%)$ of the 10322 subjects invited to undergo the iFOBT underwent and returned the test. Women (63\%) participated more often than men (56\%) and persons $<60$ years of age a little less than persons $\geqslant 60$ years of age $(59 v s 61 \%)$ (Table 1$)$. A positive iFOBT, i.e., a test result $\geqslant 50 \mathrm{ng} \mathrm{ml}^{-1}$, was found in 526 subjects, corresponding with a positivity rate of $8.5 \%$ (95\% CI: $7.8-$ 9.2) of participants. The positivity rate was $6.6 \%$ for women and $10.9 \%$ for men and, respectively, 6.4 and $10.8 \%$ for participants $<60$ and $\geqslant 60$ years of age. The age of one iFOBT positive female was unknown.

In $428(81 \%)$ of these 526 patients, a colonoscopy was carried out, which constituted a colonoscopy rate (positive participants adherent to colonoscopy) of $7 \%$. The caecum was reached in 402 patients $(94 \%)$. In the 26 patients in whom the caecum could not be reached during the first colonoscopy, a successful second colonoscopy was carried out. In three of the stage III CRC patients, the second colonoscopy was not completed because of the obstructing tumour, instead a computerised tomography colonography was carried out. 
Table I Basic numbers and descriptive statistics of the study population invited to perform an iFOBT in population based colorectal cancer screening

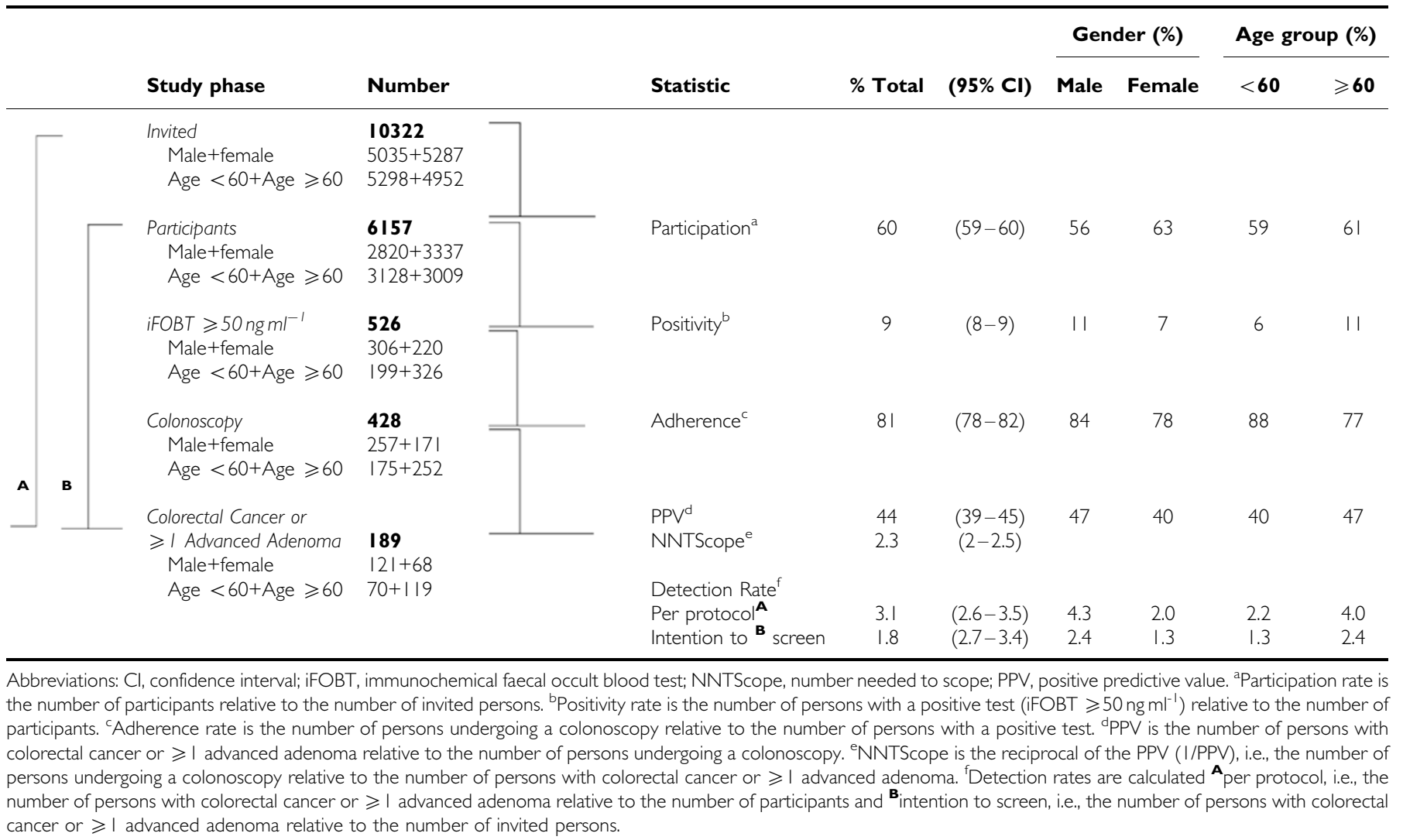

Table 2 Characteristics of lesions found at colonoscopy and iFOBT result $\left(\mathrm{ng} \mathrm{ml}^{-1}\right)$

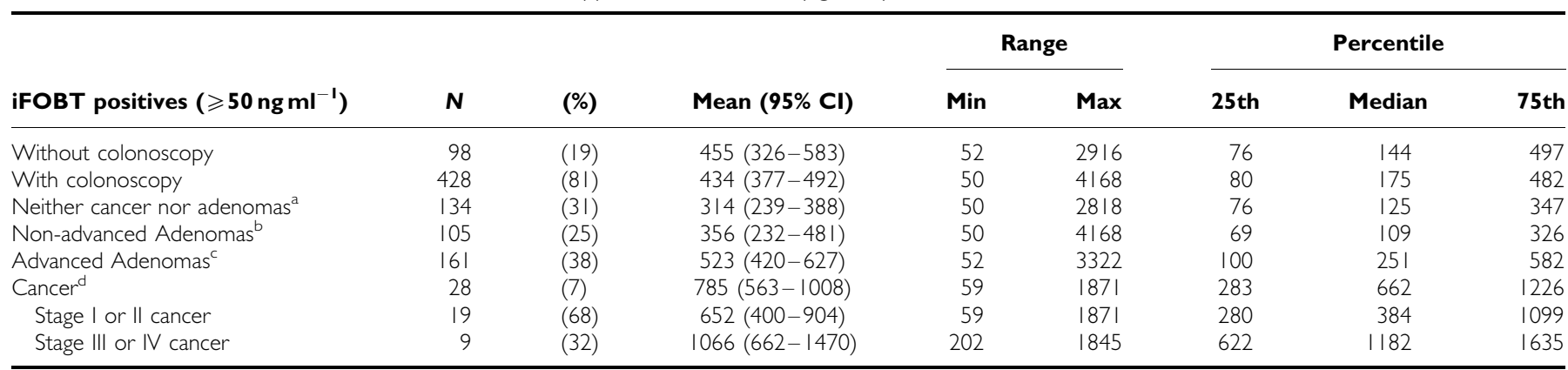

Abbreviation: iFOBT, immunochemical faecal occult blood test. ${ }^{a}$ Neither cancer nor adenomas: colonoscopies without any lesions or only hyperplastic polyps, serrated adenomas

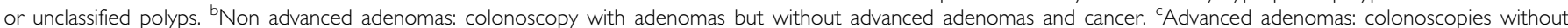
cancer but with adenomas $\geqslant 10 \mathrm{~mm}$ in size, high grade dysplasia or a villous component $\geqslant 20 \%$. ${ }^{\mathrm{S}}$ Staging according to TNM classification: there were only 4 stage $\|$ (all stage $\mathrm{lla}$, none stage IIb) and no stage IV patients. Therefore, stages I and II, and III and IV were combined.

\section{Per-polyp analysis}

In total, 644 adenomas and 28 carcinomas were detected in 294 patients. Of the 266 patients without cancer, 161 patients had in total 250 advanced adenomas, of which $167(67 \%)$ were $\geqslant 1 \mathrm{~cm}$, $66(26 \%)$ had high-grade dysplasia, $19(8 \%)$ were completely villous and $164(66 \%)$ were considered to have $\geqslant 20 \%$ villous aspects.

\section{Per patient analysis}

CRC was detected in $28(7 \%)$ of the 428 patients, and in $161(38 \%)$ patients at least 1 advanced adenoma was detected (Table 2). Thus, 189 patients had either CRC or $\geqslant 1$ advanced adenoma, which amounts to $44 \%$ (95\% CI: $40-49 \%$ ) of the patients who underwent colonoscopy for a positive test. Of the 161 patients with $\geqslant 1$ advanced adenoma, $137(85 \%)$ had one or more adenomas $\geqslant 1 \mathrm{~cm}$ and 20 patients $(6 \%)$ had advanced adenomas on the basis of villous aspects only.

\section{iFOBT performance}

The iFOBT test results ranged from 0 to $4186 \mathrm{ng} \mathrm{ml}^{-1}$ haemoglobin. The mean amount of haemoglobin detected in iFOBTpositive subjects without CRC or advanced adenomas was $314 \mathrm{ng} \mathrm{ml}^{-1}$ (95\% CI: 239-388) (Table 2), which was significantly lower than the mean amount of $785 \mathrm{ng} \mathrm{ml}^{-1}(95 \% \mathrm{CI}: 563-1008)$ in patients with CRC and $523 \mathrm{ng} \mathrm{ml}^{-1}$ (95\% CI: 420-627) in patients 


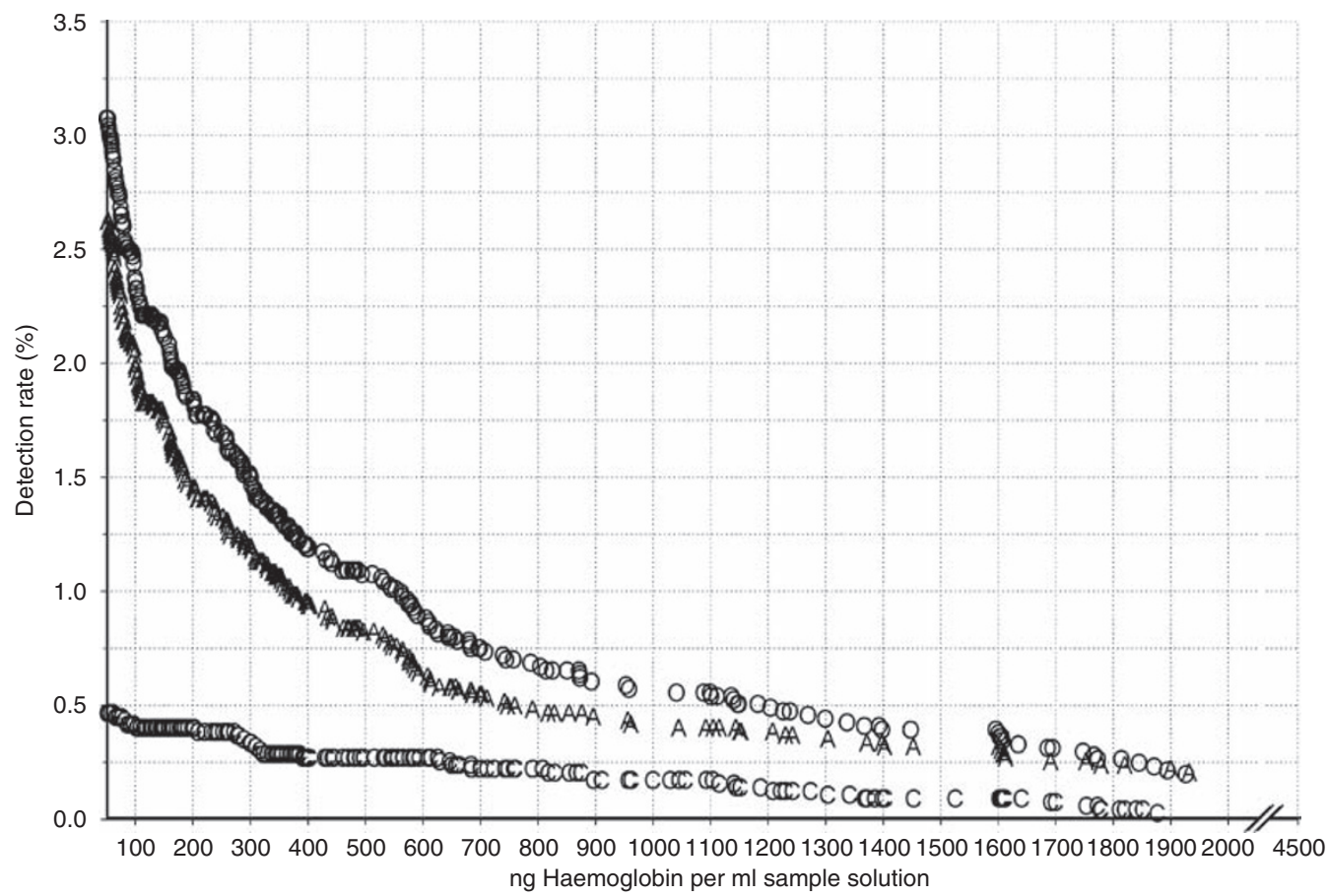

Figure I The detection rate (\%) for colorectal cancer and advanced adenomas for the operative range of the immunochemical faecal occult blood test (iFOBT) $\left(50-2000 \mathrm{ng} \mathrm{m}^{-1}\right)$. Overall detection rate of colorectal cancer and advanced adenomas (O), subgroup detection rates of colorectal cancer (C) and advanced adenomas (A) (adenomas $\geqslant 10 \mathrm{~mm}$, adenomas with high-grade dysplasia or adenomas with a villous component $\geqslant 20 \%$ ).

with $\geqslant 1$ advanced adenoma. The amount of haemoglobin in the faecal sample does not follow a normal distribution; the median is lower than the mean. The difference in the amount of haemoglobin in the sample of patients with CRC or $\geqslant 1$ advanced adenoma compared with patients without significant lesions is therefore less pronounced than the averages indicated in Table 2. By logarithmic transformation of the test value, a normal distribution for the (log) amount of haemoglobin was reached. Univariable logistic regression analysis showed quantity-response relations for the log-transformed test value and the likelihood of finding CRC $(P<0.0001)$, stage I or II CRC $(P<0.01)$, stage III or IV CRC $(P<0.001)$ or advanced adenomas $(P<0.001)$. In reality, only four patients with a stage II CRC were observed, and none with stage IIb and stage IV. Correction with logistic regression analysis for the possible confounders, age and gender, did not change any of the relations found, and statistical significance was robust for all groups.

Although the results ranged from 0 to $4186 \mathrm{ng} \mathrm{ml}^{-1}$, in Figure 1, the detection rates for CRC and advanced adenomas are presented for a maximum of $2000 \mathrm{ng} \mathrm{ml}^{-1}$. Besides the overall detection rates for CRC and advanced adenomas, separate detection rates for CRC and advanced adenomas are presented as well. At a cutoff value of $50 \mathrm{ng} \mathrm{ml}^{-1}$, the overall detection rate for CRC and advanced adenomas was $3.1 \%(95 \% \mathrm{CI}: 2.6-3.5)$, and the NNTScope was 2.3 (95\% CI: $2.2-2.3$ ) (Figure 2 and Table 3). At the cutoff value $>75 \mathrm{ng} \mathrm{ml}^{-1}$, the detection rate was $2.7 \%$ and the NNTScope was 2, that is, in every second colonoscopy, a patient with CRC or at least one advanced adenoma was detected. At this level one patient with stage I cancer was excluded on comparing with the cutoff value of $50 \mathrm{ng} \mathrm{ml}^{-1}$. At a cutoff value of $100 \mathrm{ng} \mathrm{ml}^{-1}$, the overall detection rate for CRC and advanced adenomas was $2.4 \%$ (95\% CI: $2.0-2.7)$, and the NNTScope was 1.9 (95\% CI: $1.9-2.0)$. At a cutoff value of $200 \mathrm{ng} \mathrm{ml}^{-1}$, the colonoscopy rate decreased by $>50 \%$ compared with $50 \mathrm{ng} \mathrm{ml}^{-1}$, that is, $50 \%$ less colonoscopies had to be carried out. At this level, the detection rate for CRC and advanced adenomas was $1.8 \%$ (95\% CI: 1.5-2.2) and the
NNTScope was 1.8 (95\% CI: 1.7-1.8). In the range from $100-$ $200 \mathrm{ng} \mathrm{ml}^{-1}$, the cancer miss rate compared with the cutoff value $\geqslant 50 \mathrm{ng} \mathrm{ml}^{-1}$ was stable at $14 \%(N=4)$.

According to Table 3, a decrease in the cutoff value from $100 \mathrm{ng} \mathrm{ml}^{-1}$ to $50 \mathrm{ng} \mathrm{ml}^{-1}$ resulted in increasing detection rates of advanced lesions from 2.4 to $3.1 \%$, but at the cost of more colonoscopies that needed to be carried out, from 4.5 to $7 \%$, and higher rates of colonoscopies without significant lesions. Increasing the cutoff value from 100 to $200 \mathrm{ng} \mathrm{ml}^{-1}$ decreases the detection rate for advanced adenomas substantially from 2.4 to $1.8 \%$, not affecting the detection rate for cancer. The colonoscopy rate is reduced to $50 \%$ by using a cutoff value of $200 \mathrm{ng} \mathrm{ml}^{-1}$ compared with $50 \mathrm{ng} \mathrm{ml}^{-1}(3.2 \mathrm{vs} 7 \%)$. The cancer miss rate at $200 \mathrm{ng} \mathrm{ml}^{-1}$ compared with $50 \mathrm{ng} \mathrm{ml}^{-1}$ is $14 \%$.

In Figure $3 \mathrm{~A}-\mathrm{D}$, the relation between detection rates and NNTScope for subjects $<60$ years and $\geqslant 60$ years, and for men and women, is presented.

\section{DISCUSSION}

We evaluated the performance and efficiency of a semi-quantitative iFOBT, the OC-Sensor, in an average-risk screening population. We presented detection rates and numbers needed to scope over the complete effective range of the test, and we have shown that, below the threshold of $100 \mathrm{ng} \mathrm{ml}^{-1}$ recommended by the manufacturer of the test, even at the lowest functional value of $50 \mathrm{ng} \mathrm{ml}^{-1}$ tested, the performance could be considered acceptable. At the $50 \mathrm{ng} \mathrm{ml}^{-1}$ level, both cancer and advanced adenomas were detected at the cost of significantly more colonoscopies. At higher cutoff levels than the standard $100 \mathrm{ng} \mathrm{ml}^{-1}$, significantly less colonoscopies have to be carried out; moreover, compared with $100 \mathrm{ng} \mathrm{ml}^{-1}$, the cancer miss rate was nil but the miss rate of advanced adenomas was substantial.

In a previous publication, we demonstrated that the performance of the G-FOBT, Hemoccult-II, is lower than the performance of 


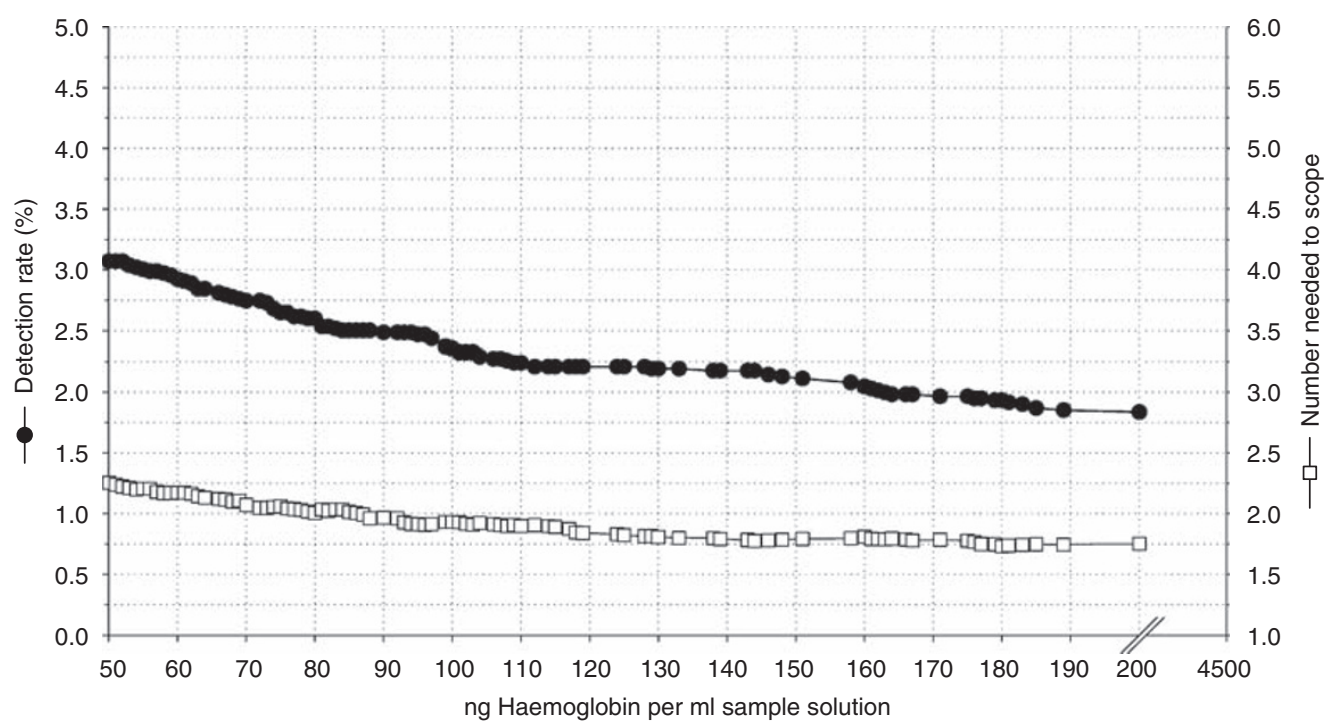

Figure 2 The overall detection rate and number needed to scope for cancer and $\geqslant 1$ advanced adenomas focused on the range between 50 and $200 \mathrm{ng} \mathrm{ml}^{-1}$. Left axis: detection rate for colorectal cancer and advanced adenomas (-) Right axis: number needed to scope for colorectal cancer and advanced adenomas (- $\square-$ ) (by definition $\geqslant 1.0$ ).

Table 3 The performance characteristics of the iFOBT, OC-Sensor, at different cutoff levels

\begin{tabular}{|c|c|c|c|c|c|c|c|c|}
\hline & \multicolumn{8}{|c|}{ Cutoff values (ng ml ${ }^{-1}$ ) } \\
\hline & 50 & 75 & 100 & 125 & 150 & 175 & 200 & 225 \\
\hline \multicolumn{9}{|l|}{ Number of lesions ( $n$ ) } \\
\hline Colorectal cancer & 28 & 27 & 24 & 24 & 24 & 24 & 24 & 23 \\
\hline CRC+advanced adenomas & 189 & 163 & 145 & 136 & 131 & 121 & 113 & 109 \\
\hline Colorectal cancer & $0.45 \%$ & $0.44 \%$ & $0.39 \%$ & $0.39 \%$ & $0.39 \%$ & $0.39 \%$ & $0.39 \%$ & $0.37 \%$ \\
\hline Confidence interval (95\% Cl) & $0.3-0.6 \%$ & $0.3-0.6 \%$ & $0.2-0.6 \%$ & $0.2-0.6 \%$ & $0.2-0.6 \%$ & $0.2-0.6 \%$ & $0.2-0.6 \%$ & $0.2-0.5 \%$ \\
\hline CRC+advanced adenomas & $3.1 \%$ & $2.6 \%$ & $2.4 \%$ & $2.2 \%$ & $2.1 \%$ & $2.0 \%$ & $1.8 \%$ & $1.8 \%$ \\
\hline Confidence interval $(95 \% \mathrm{Cl})$ & $2.6-3.5 \%$ & $2.3-3.1 \%$ & $2-2.7 \%$ & $1.8-2.6 \%$ & $1.8-2.5 \%$ & $1.6-2.3 \%$ & $1.5-2.2 \%$ & $1.4-2.1 \%$ \\
\hline \multicolumn{9}{|l|}{ Number Needed To Scope ${ }^{d}(\mathrm{~N} / \mathrm{n})$} \\
\hline Colorectal cancer & 15.3 & 12.4 & 11.7 & 10.3 & 9.8 & 9.0 & 8.3 & 8.1 \\
\hline CRC+advanced adenomas & $96.0 \%$ & $97.1 \%$ & $97.8 \%$ & 98.1 & 98.3 & 98.4 & 98.6 & 98.7 \\
\hline Confidence interval (95\% Cl) & $95.5-96.5 \%$ & $96.7-97.5 \%$ & $97.4-98.1 \%$ & $97.8-98.5 \%$ & $98.0-98.6 \%$ & $98.1-98.8 \%$ & $98.3-98.9 \%$ & $98.4-99.0 \%$ \\
\hline CRC miss rate ${ }^{f}(\%)$ & N.A. & $3.6 \%$ & $14.3 \%$ & $14.3 \%$ & $14.3 \%$ & $14.3 \%$ & $14.3 \%$ & $17.9 \%$ \\
\hline Confidence interval (95\% Cl) & N.A. & $-3.3-10.4 \%$ & $1.3-27.2 \%$ & $1.3-27.2 \%$ & $1.3-27.2 \%$ & $1.3-27.2 \%$ & $1.3-27.2 \%$ & $3.7-32 \%$ \\
\hline
\end{tabular}

Abbreviations: Cl, confidence interval; CRC, colorectal cancer, iFOBT, immunochemical faecal occult blood test. aPostives adherent to colonoscopy = patients with a positive iFOBT who underwent a colonoscopy. ${ }^{\mathrm{b}}$ Colonoscopy rate $=$ percentage of participants with a positive iFOBT who underwent a colonoscopy. ${ }^{\circ}$ Detection rate $=$ percentage of

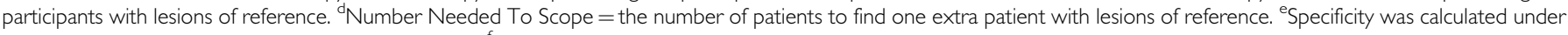
the rare disease assumption (Brecht and Robra, 1987). ${ }^{\mathrm{f}} \mathrm{CRC}$ miss rate $=$ the percentage of the colorectal cancer patients at that cutoff relative to the colorectal cancer patients at the minimal $50 \mathrm{ng} \mathrm{ml}^{-1}$ cutoff.

the iFOBT, OC-Sensor, at the standard cutoff value of $100 \mathrm{ng} \mathrm{ml}^{-1}$ (Van Rossum et al, 2008). The PPV for CRC and advanced adenomas of the G-FOBT was $55.3 \%$, which was reached with the iFOBT at a cutoff of $130 \mathrm{ng} \mathrm{ml}^{-1}$. At this cutoff, the NNTScope of iFOBT was equal to that of G-FOBT, but the detection rate for CRC was more than 2.5 times higher for iFOBT compared with that for G-FOBT, and for advanced adenomas, this was almost twice as high.
The quantitative aspect of the iFOBT allows to adjust the cutoff value to a screening programme and can be based on aspects such as the intended detection rate, population-related factors (e.g., prevalence of CRC, participation rates) and political issues such as colonoscopy capacity. The cutoff value with the most optimal performance of the iFOBT may differ in various populations and may change over time, because the performance is dependent on the prevalence of CRC and advanced adenomas. Therefore, the data 

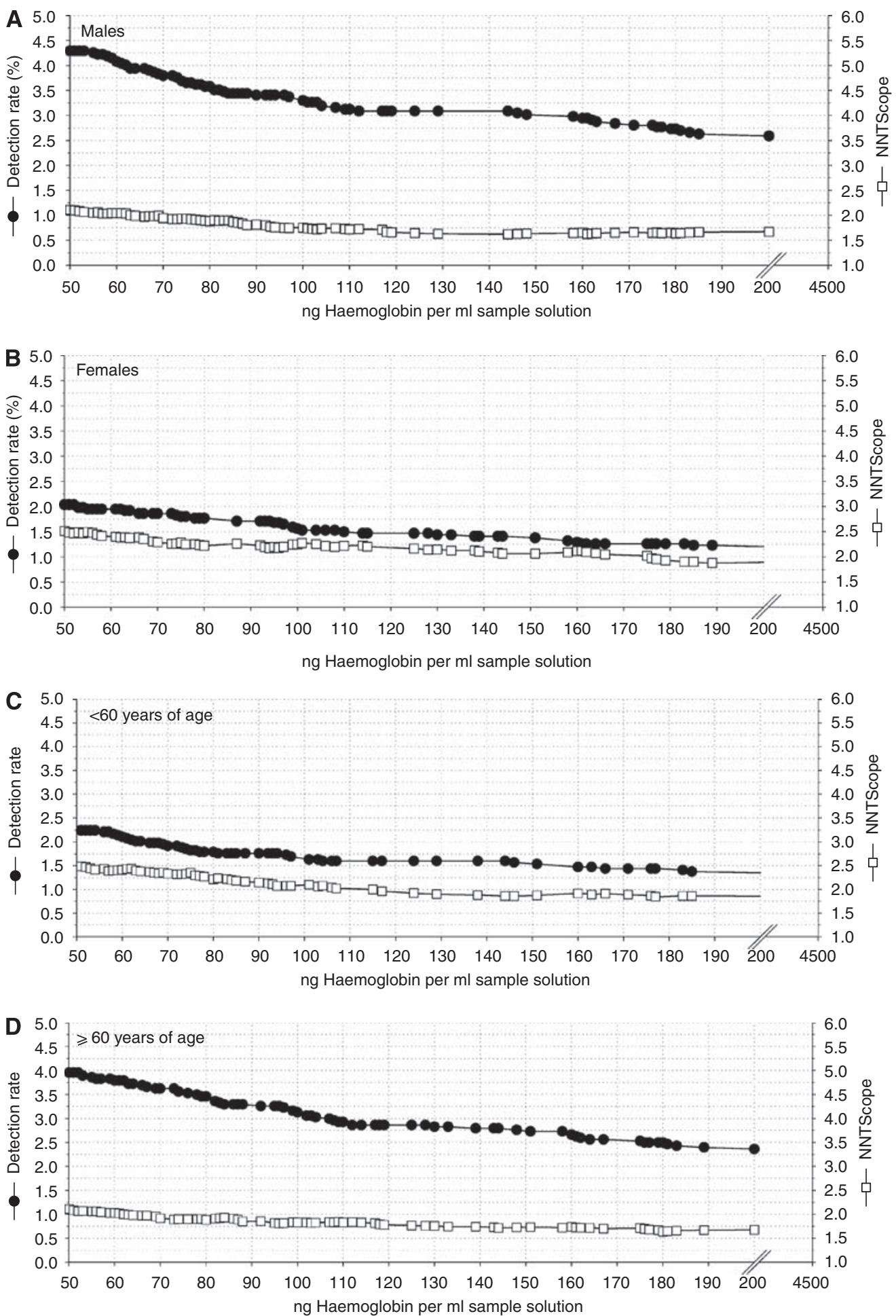

Figure 3 The detection rate (\%) and number needed to scope for colorectal cancer and $\geqslant 1$ advanced adenomas focused on the range between 50 and $200 \mathrm{ng} \mathrm{ml}^{-1}$ for males $(\mathbf{A})(N=257)$, for females $(\mathbf{B})(N=17 \mathrm{I})$, patients $<60$ years of age $(\mathbf{C})(N=252)$ and for patients $\geqslant 60$ years of age $(\mathbf{D})(N=175)$. Left axis: detection rate for colorectal cancer and advanced adenomas (- -). Right axis: number needed to scope (NNTScope) for colorectal cancer and advanced adenomas (- $\square$-) (by definition $\geqslant 1.0$ ).

from this study should not be extrapolated to other populations, without considering these variables. However, we do think extrapolation of results will be quite appropriate for most European countries, as the prevalence of CRC and the capacity of adequate health care are comparable (Regula et al, 2006; Segnan et al, 2007).
With regard to colonoscopy capacity, the colonoscopy rate of $7 \%$ at the lowest cutoff value of $50 \mathrm{ng} \mathrm{ml}^{-1}$ could be considered acceptable if compared with that of countries with primary colonoscopy screening, Moreover, in case of a colonoscopy because of a positive iFOBT, the positive predictive value for 
advanced lesions will be substantially higher than in persons undergoing primary colonoscopy screening.

Previous studies published regarding semi-quantitative iFOBTs in screening populations did not address the true continuous nature of these tests (Castiglione et al, 2002; Guittet et al, 2007). Furthermore, these studies did not present colonoscopy results below the threshold recommended by the manufacturer. In a recent study on 1000 symptomatic and other high-risk patients in Israel with the same OC-Sensor test from Eiken Chemical, cutoff values below the recommended threshold were evaluated (Levi et al, 2007). The results of this study are comparable with our results, and the authors suggested that a cutoff level of $75 \mathrm{ng} \mathrm{ml}^{-1}$ would probably achieve optimal results, acknowledging the fact that population-based screening data are needed for confirmation.

A limitation of our study was that we only have data for one sample of iFOBT. In the previously mentioned study, 1000 symptomatic and other high-risk patients in Israel were asked to undergo three separate sample tests (Levi et al, 2007). The authors observed an increased sensitivity for more than one sample, although the difference between two and three samples was not significant and the specificity decreased when more samples were used. It is conceivable that a screening strategy with two samples results in a different optimal cutoff value when compared with one sample screening. However, an increase in sensitivity and therefore detection rate by two tests could be matched by a decrease in participation rate, resulting in a decrease in detection rate according to an intention-to-screen analysis.

It is unavoidable in population-based screening studies with a two tier model (that is, colonoscopy only under the condition of a positive pretest) to not offer a colonoscopy to iFOBT negatives; therefore, sensitivity of the iFOBT could not be calculated in this study. However, the sensitivity of the iFOBT could possibly be estimated for the purposes of cost-effectiveness studies, provided extensive sensitivity analyses are carried out for incidence and prevalence, because incidence and prevalence of colorectal cancer seem quite similar in most European countries (Regula et al, 2006; Ferlay et al, 2007; Segnan et al, 2007; Hundt et al, 2009).

Of the participants with a positive iFOBT, $19 \%$ did not adhere to the colonoscopy. Similar percentages have been observed in other population-based screening studies (Faivre et al, 2004). While designing our study (using municipal databases), we were unable to carry out a pre-selection according to eligibility. Therefore, this percentage consists of those individuals who refused to undergo colonoscopy, and also individuals who were excluded for colonoscopy because of, e.g., severe co-morbidity or recent colonoscopy. As we conducted an implementation study, we did not exclude these patients from the $19 \%$ who were not adherent to colonoscopy.

The villous component for advanced adenoma status can be difficult to evaluate, especially if the level is on the predefined limit of $20 \%$. However, the percentage of patients with a colonoscopy with only a villous component as the criterion for advanced adenoma status was $6 \%$ of all patients. Of all patients with advanced adenomas, $85 \%$ had at least an adenoma $\geqslant 10 \mathrm{~mm}$ in size. Even if all 20 patients with only a villous component had been excluded from the group with advanced adenomas, our conclusions would have remained identical.

Advanced adenomas and CRC were found more often in men than in women, and advanced adenomas and CRC were also more often detected in older persons. This is in line with other studies (Manus et al, 1997; Betes et al, 2003; Sedjo et al, 2007). Thus, the diagnostic yield increases with age and male gender. We showed that for gender and different age groups, other optimal cutoff values might be valid, but with the present data, we were unable to verify the validity of any specific recommendations. It might be interesting to investigate the possibility, as well as the acceptability, of age- and gender-specific cutoff values.

In conclusion: This study presents evidence that, below the standard threshold of $100 \mathrm{ng} \mathrm{ml}^{-1}$, which is recommended by the manufacturer of the iFOBT OC-Sensor, acceptable performance could be achieved even at the lowest functional value of $50 \mathrm{ng} \mathrm{ml}^{-1}$. Substantially higher detection rates for colorectal cancer and for advanced adenomas correspond with increasing numbers needed to be scoped. However, the positivity rate and the resulting number of colonoscopies to be carried out are relatively high compared with higher cutoff values $\left(100-200 \mathrm{ng} \mathrm{ml}^{-1}\right)$. We propose that a cutoff value below $100 \mathrm{ng} \mathrm{ml}^{-1}$ would be feasible and acceptable in screening programmes in many Western European countries, assuming resources and colonoscopy capacity are sufficient. However, when resources and colonoscopy capacity are not sufficient, cutoff values above $100 \mathrm{ng} \mathrm{ml}^{-1}$ (up to $200 \mathrm{ng} \mathrm{ml}^{-1}$ ) will result in a relatively limited miss rate for colorectal cancer and a lower but still quite high detection rate of advanced adenomas at the expense of a decrease in the total number of colonoscopies to be carried out. Policy makers will determine the optimal cutoff value on the basis of a largely arbitrary balance between the acceptability of missing cancer and the possibility and acceptability of assigning essential resources. In the Netherlands, there is indication that a cutoff of $75 \mathrm{ng} \mathrm{ml}^{-1}$ is considered for implementation in national screening.

\section{ACKNOWLEDGEMENTS}

We thank the Comprehensive Cancer Centre, Amsterdam for their support during the course of study in Amsterdam. This study was supported by grants from The Netherlands Organization for Health Research and Development (ZonMW: number 50-50115-98060, project 63000004 ).

\section{Conflict of interest}

The authors declare no conflict of interest.

\section{REFERENCES}

Betes M, Munoz-Navas MA, Duque JM, Angos R, Macias E, Subtil JC, Herraiz M, De La Riva S, Delgado-Rodriguez M, Martinez-Gonzalez MA (2003) Use of colonoscopy as a primary screening test for colorectal cancer in average risk people. Am J Gastroenterol 98: 2648-2654

Brecht JG, Robra BP (1987) A graphic method of estimating the specificity of screening programmes from incomplete follow-up data. Methods Inf Med 26: 53-58

Castiglione G, Grazzini G, Miccinesi G, Rubeca T, Sani C, Turco P, Zappa M (2002) Basic variables at different positivity thresholds of a quantitative immunochemical test for faecal occult blood. J Med Screen 9: 99-103

Chiang CH, Jeng JE, Wang WM, Jheng BH, Hsu WT, Chen BH (2006) A comparative study of three fecal occult blood tests in upper gastrointestinal bleeding. Kaohsiung J Med Sci 22: 223-228
Faivre J, Dancourt V, Lejeune C, Tazi MA, Lamour J, Gerard D, Dassonville F, Bonithon-Kopp C (2004) Reduction in colorectal cancer mortality by fecal occult blood screening in a French controlled study. Gastroenterology 126: $1674-1680$

Fenocchi E, Martinez L, Tolve J, Montano D, Rondan M, Parra-Blanco A, Eishi Y (2006) Screening for colorectal cancer in Uruguay with an immunochemical faecal occult blood test. Eur J Cancer Prev 15: $384-390$

Ferlay J, Autier P, Boniol M, Heanue M, Colombet M, Boyle P (2007) Estimates of the cancer incidence and mortality in Europe in 2006. Ann Oncol 18: $581-592$

Grazzini G, Castiglione G, Ciabattoni C, Franceschini F, Giorgi D, Gozzi S, Mantellini P, Lopane P, Perco M, Rubeca T, Salvadori P, Visioli CB, 
Zappa M (2004) Colorectal cancer screening programme by faecal occult blood test in Tuscany: first round results. Eur J Cancer Prev 13: 19-26 Grazzini G, Visioli CB, Zorzi M, Ciatto S, Banovich F, Bonanomi AG, Bortoli A, Castiglione G, Cazzola L, Confortini M, Mantellini P, Rubeca T, Zappa M (2009) Immunochemical faecal occult blood test: number of samples and positivity cutoff. What is the best strategy for colorectal cancer screening? Br J Cancer 100: 259-265

Guittet L, Bouvier V, Mariotte N, Vallee JP, Arsene D, Boutreux S, Tichet J, Launoy G (2007) Comparison of a guaiac based and an immunochemical faecal occult blood test in screening for colorectal cancer in a general average risk population. Gut 56: $210-214$

Hundt S, Haug U, Brenner H (2009) Comparative evaluation of immunochemical fecal occult blood tests for colorectal adenoma detection. Ann Intern Med 150: $162-169$

Itoh M, Takahashi K, Nishida H, Sakagami K, Okubo T (1996) Estimation of the optimal cut off point in a new immunological faecal occult blood test in a corporate colorectal cancer screening programme. J Med Screen 3: $66-71$

Levi Z, Rozen P, Hazazi R, Vilkin A, Waked A, Maoz E, Birkenfeld S, Leshno M, Niv Y (2007) A quantitative immunochemical fecal occult blood test for colorectal neoplasia. Ann Intern Med 146: 244-255

Manus B, Adang RP, Ambergen AW, Bragelmann R, Armbrecht U, Stockbrugger RW (1997) The risk factor profile of recto-sigmoid adenomas: a prospective screening study of 665 patients in a clinical rehabilitation centre. Eur J Cancer Prev 6: 38 - 43

Minami Y, Nishino Y, Tsubono Y, Tsuji I, Hisamichi S (2006) Increase of colon and rectal cancer incidence rates in Japan: trends in incidence rates in Miyagi Prefecture, 1959-1997. J Epidemiol 16: 240-248

O'Connell JB, Maggard MA, Ko CY (2004) Colon cancer survival rates with the new American Joint Committee on Cancer sixth edition staging. $J$ Natl Cancer Inst 96: 1420-1425

Regula J, Rupinski M, Kraszewska E, Polkowski M, Pachlewski J, Orlowska J, Nowacki MP, Butruk E (2006) Colonoscopy in colorectal-cancer screening for detection of advanced neoplasia. New Engl J Med 355: 1863-1872
Rubeca T, Rapi S, Confortini M, Brogioni M, Grazzini G, Zappa M, Puliti D, Castiglione G, Ciatto S (2006) Evaluation of diagnostic accuracy of screening by fecal occult blood testing (FOBT). Comparison of FOB Gold and $\mathrm{OC}$ Sensor assays in a consecutive prospective screening series. Int J Biol Markers 21: 157-161

Schlemper RJ, Riddell RH, Kato Y, Borchard F, Cooper HS, Dawsey SM, Dixon MF, Fenoglio-Preiser CM, Flejou JF, Geboes K, Hattori T, Hirota T, Itabashi M, Iwafuchi M, Iwashita A, Kim YI, Kirchner T, Klimpfinger M, Koike M, Lauwers GY, Lewin KJ, Oberhuber G, Offner F, Price AB, Rubio CA, Shimizu M, Shimoda T, Sipponen P, Solcia E, Stolte M, Watanabe H, Yamabe H (2000) The Vienna classification of gastrointestinal epithelial neoplasia. Gut 47: $251-255$

Sedjo RL, Byers T, Levin TR, Haffner SM, Saad MF, Tooze JA, D’Agostino Jr RB (2007) Change in body size and the risk of colorectal adenomas. Cancer Epidemiol Biomarkers Prev 16: 526-531

Segnan N, Senore C, Andreoni B, Azzoni A, Bisanti L, Cardelli A, Castiglione G, Crosta C, Ederle A, Fantin A, Ferrari A, Fracchia M, Ferrero F, Gasperoni S, Recchia S, Risio M, Rubeca T, Saracco G, Zappa M (2007) Comparing attendance and detection rate of colonoscopy with sigmoidoscopy and FIT for colorectal cancer screening. Gastroenterology 132: $2304-2312$

Sohn DK, Jeong SY, Choi HS, Lim S, Huh JM, Kim DH, Kim YH, Chang HJ, Jung KH, Ahn JB, Kim HK, Park JG (2005) Single immunochemical fecal occult blood test for detection of colorectal neoplasia. Cancer Res Treat 37: $20-23$

Van Rossum LG, Van Rijn AF, Laheij RJ, Van Oijen MG, Fockens P, Van Krieken HH, Verbeek AL, Jansen JB, Dekker E (2008) Random comparison of guaiac and immunochemical fecal occult blood tests for colorectal cancer in a screening population. Gastroenterology 135: $82-90$

Vilkin A, Rozen P, Levi Z, Waked A, Maoz E, Birkenfeld S, Niv Y (2005) Performance characteristics and evaluation of an automated-developed and quantitative, immunochemical, fecal occult blood screening test. Am J Gastroenterol 100: 2519-2525 